\title{
Perubahan Individu dalam Organisasi Puskesmas:Studi Kasus Revitalisasi Puskesmas di Kabupaten Sumedang
}

\author{
Nina Triana, ${ }_{1}$ Elsa Pudji Setiawati, ${ }^{2}$ Insi Farisa Desy Arya, ${ }^{2}$ Deni K Sunjaya, ${ }^{2}$ Dadi S Argadiredja, ${ }^{2}$ \\ Dewi Marhaeni Diah Herawati \\ ${ }^{1}$ Dinas Kesehatan Kabupaten Sumedang Indonesia, ${ }^{2}$ Departemen Ilmu Kesehatan Masyarakat Fakultas \\ Kedokteran Universitas Padjadajaran
}

\begin{abstract}
Abstrak
Revitalisasi Puskesmas merupakan upaya Kementerian Kesehatan RI untuk meningkatkan kinerja Puskesmas melalui berbagai perubahan dalam penyelenggaraan Puskesmas. Perubahan-perubahan tersebut sejalan dengan semangat reformasi pembangunan khususnya reformasi otonomi daerah. Penelitian ini bertujuan untuk menganalisis manajemen perubahan oleh individu Puskesmas. Metode Desain penelitian yang dipergunakan adalah kualitatif dengan paradigma konstruktivism dan strategi studi kasus. Metode analisis yang digunakan adalah tematik. Subyek penelitian ini adalah tenaga Puskesmas Situ dan Puskesmas Paseh di Kabupaten Sumedang. Hasil model manajemen perubahan $A D K A R$ mendukung hasil yang menunjukkan bahwa konstruk perubahan individu Puskesmas didasari oleh tahap-tahap yang harus berurutan. Perubahan oleh individu dalam revitalisasi Puskesmas tidak terbangun secara utuh sehingga memengaruhi pencapaian perubahan yang diharapkan. Simpulan Sadar, mau, mencari tahu, mampu, dan siap dalam perubahan adalah keputusan individu yang merupakan hasil keterampilan menyelesaikan persaingan dorongan dalam dirinya. Keputusan-keputusan itulah yang merupakan motif individu untuk melakukan perilaku perubahan yang terhimpun dalam aktifitas perubahan untuk apapun bentuk perubahan organisasi yang dilakukan.
\end{abstract}

Kata kunci: $A D K A R$, Manajemen Perubahan, Revitalisasi Puskesmas

\section{Individual Change in PHC Organization a Case Study on PHC Revitalization in Sumedang District}

\begin{abstract}
Revitalization of PHC is an effort of the Indonesia's Ministry of Health to improve the performance of health centers through various changes in the implementation of $\mathrm{PHC}$ reforms. The changes are in line with the spirit of development reform, especially reform of the district autonomy. This study aims to explore the management of change in PHC revitalization undertaken by the Sumedang District Government through the District Department of Health and analyze the management of change by PHC staff. Method This research used qualitative design with konstruktivism paradigm and case study strategies. The analytical method used was thematic. The subjects of this study is the PHC staff at Puskesmas Situ and Puskesmas Paseh in Sumedang District. Results the change management model ADKAR support results show that construct individual changes PHC constituted by stages that must be sequential. Changes by individual in the PHC revitalization in Sumedang District was not fully awakened to affect the achievement of the expected changes. Discussion conscious, want to find out, able, and ready to change is an individual decision that is the result of solving skill competition urge in him. Decisions that is what is the motive of individuals to make the behavior changes that accumulate in the activities of changes to any form of organizational change undertaken.
\end{abstract}

Keywords: ADKAR, Change Management, PHC Revitalization

Korespondensi:

Nina Triana

Dinas Kesehatan Kabupaten Sumedang

Jl. Kutamaya No. 21 Sumedang 45312

Mobile : 085221589655

Email : ninatriana28@yahoo.com 


\section{Pendahuluan}

Perubahan yang terjadi pada penyelenggaraan Puskesmas merupakan wujud dari desentralisasi, otonomi daerah dan reformasi pembangunan di Indonesia yang lebih luas, nyata, dan bertanggung jawab. Hal ini telah memungkinkan daerah untuk menjalankan insiatif dan prakarsa sendiri dalam melaksanakan pembangunan tanpa intervensi dan kontrol yang berlebihan dari pemerintah pusat.

Desentralisasi bidang kesehatan bertujuan agar program pembangunan kesehatan lebih efektif dan efisien serta menyentuh kebutuhan masyarakat sehingga keberhasilan desentralisasi sangat tergantung pada kesiapan daerah untuk menerapkannya. ${ }^{1}$ Hasil evaluasi setelah 5 (lima) tahun implementasi reformasi otonomi daerah dalam sektor kesehatan di Indonesia yang mengacu pada UUNomor 22 Tahun 1999 dan UU Nomor 25 Tahun 1999 masih menujukkan adanya permasalahan. Salah satu contohnya adalah masih terdapat dana bagi berbagai proyek kesehatan yang tidak diimbangi dengan dana operasional. ${ }^{2}$

Ketidaksiapan berbagai daerah saat kebijakan otonomi daerah diberlakukan, berdampak kurang menguntungkan bagi puskesmas, antara lain kurangnya biaya operasional puskesmas sehingga berdampak pada penurunan kinerja Puskesmas. ${ }^{3}$ Puskesmas yang seharusnya lebih mengutamakan upaya promotif dan preventif sebagai bagian dari Upaya Kesehatan Masyarakat, menjadi lebih memprioritaskan upaya kuratif sebagai bagian dari Upaya Kesehatan Perorangan (UKP). ${ }^{1}$ Di pihak lain, berdasarkan konsep Puskesmas yang diperkenalkan pada tahun 1968 puskesmas tidak semata-mata hanya sebagai balai pengobatan untuk warga yang sakit, melainkan sebagai pusat sosialisasi gaya hidup sehat di masyarakat. ${ }^{4}$

Berbagai permasalahan yang terjadi pada puskesmas di awal implementasi desentralisasi, ditindaklanjuti oleh Departemen Kesehatan RI dengan menerbitkan Keputusan Menteri Kesehatan(KMK) Nomor 128 Tahun 2004 tentang Kebijakan Dasar Puskesmas. KMK ini merupakan pedoman yang diperuntukkan bagi pemerintah kabupaten/kota agar dapat menyelenggarakan Puskesmas sesuai dengan konsep dasarnya, sehingga diharapkan puskesmas akan memiliki

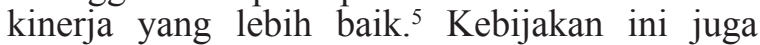
merupakan bentuk dukungan bagi pelaksanaan revitalisasi Puskesmas dalam membangun fondasi reformasi kesehatan di Indonesia. ${ }^{6}$

Pada Tahun 2005, Direktorat Jenderal Bina Kesehatan Masyarakat Depkes RI mengusulkan revitalisasi Puskesmas dan rencana aksinya, dengan tujuan mengembalikan fungsi Puskesmas kepada konsep awal, ketenagaan Puskesmas dan pemenuhan sarana dan peralatan di Puskesmas sesuai nilai-nilai dasar dalam KMK Nomor 128 Tahun 2004. Kebijakan ini mengarahkan Puskesmas agar menetapkan visi dan misi yang sesuai dengan fungsi Puskesmas sesungguhnya. KMK juga mengatur kedudukan, organisasi dan tata kerja di Puskesmas untuk mendukung berbagai upaya kesehatan yang diselenggarakan di Puskesmas sesuai dengan fungsinya pada KMK. Hal ini ditunjang dengan manajemen Puskesmas berupa rangkaian kegiatan yang bekerja secara secara sistematik dan berkesinambungan. ${ }^{1}$

Hasil evaluasi Pada Tahun 2006 menunjukkan bahwa revitalisasi Puskesmas masih merupakan wacana di tingkat nasional dan belum diterima sepenuhnya oleh petugas Puskesmas. Dalam hal ini, petugas Puskesmas belum dapat menjabarkan apa yang harus direvitalisasi pada puskesmas sehingga penyelenggaraannya menjadi tidak taat azas. ${ }^{1,7}$ Implementasi reformasi kebijakan desentralisasi sejak Tahun 2001 baru sampai pada tahap reorganisasi Puskesmas melalui penyederhanaan program pokok dan belum sampai pada pengembangan peran Puskesmas. Akibatnya, pola pelayanan Puskesmas masih fokus pada pengobatan sehingga staf Puskesmas lebih banyak memanfaatkan waktu kerjanya menunggu pasien di dalam gedung Puskesmas dan puskesmas pembantu dibandingkan proaktif mendampingi keluarga dan kelompok-kelompok masyarakat memelihara kesehatannya sendiri. ${ }^{4}$

Di Kabupaten Sumedang, perubahan pada penyelenggaraan Puskesmas di era reformasi otonomi daerah terjadi sejak Tahun 2001 yang ditandai dengan perubahan organisasi Puskesmas menjadi Unit Pelaksana Teknis Daerah (UPTD). Berdasarkan laporan kinerja Puskesmas yang belum sesuai harapan, terdapat indikasi adanya permasalahan dalam pelaksanaan revitalisasi Puskesmas di Kabupaten Sumedang. Salah satunya adalah berdasarkan indikator kinerja UKP Puskesmas dari Tahun 2008 sampai Tahun 2012 jumlah kunjungan pasien ke Puskesmas terus mengalami penurunan. Fakta lain yang semakin menguatkan adanya permasalahan revitalisasi Puskesmas di Kabupaten Sumedang adalah tidak adanya Badan Penyantun Puskesmas (BPP) sebagai bentuk realisasi dari azas pemberdayaan masyarakat yang dilakukan oleh Puskesmas.

Melalui kebijakan dasar tersebut, Puskesmas sebagaiorganisasiyangmemilikikinerjayang tidak optimal diharuskan berubah menjadi organisasi yang memiliki kinerja optimal. Pengetahuan tentang alasan bagi terjadinya perubahan dan bagaimana cara memperoleh hasil perubahan memerlukan penjelasan teori perubahan. ${ }^{8}$

Unuk dapat melakukan perubahan diperlukan langkah-langkah yang mendasar berdasarkan model-model perubahanyang telahada. Reformasi 
atau perubahan bertujuan mengubah manusia dan bukan mengubah organisasi. Padahal, berubah bukanlah suatu hal yang mudah bagi manusia karena harus berpindah dari zona kenyamanan ke zona ketidaknyamanan. ${ }^{9}$ Drummon-Hay dan Bramford menemukan banyak sekali "subyek hidup" yang merupakan agen bagi perubahan dalam pelayanan kesehatan di United Kingdom. ${ }^{10}$

Kinerja organisasi sangat ditentukan oleh kinerja sumber daya manusia yang berada dalam organisasitersebut. ${ }^{11}$ Pengabaianterhadapmanusia sebagai pelaku perubahan dalam organisasi dapat merupakan salah satu penyebab ketidakberhasilan perubahan organisasi. Terdapat sebuah model manajemen perubahan yang dianggap efektif karena mengedepankan sisi manusia dalam melakukan perubahan yaitu ADKAR (Awareness, Desire, Knowledge, Ability, dan Reinforcement). ${ }^{12}$

Model ini berhasil mengukur kompetensi manajemen perubahan yang terjadi pada setiap individu dalam suatu organisasi. ${ }^{13}$ Model manajemen perubahan ini adalah model yang modern hasil pengembangan Jeffrey M. Hiatt seorang $C E O$ pada lembaga penelitian bernama Prosci Research Foundation sejak Tahun 1996. Hiatt mengemukakan model perubahan yang berorientasi pada tujuan/hasil yaitu keberhasilan perubahan individu dalam organisasi sebagai keberhasilan perubahan organisasi. Dalam hal ini, keberhasilan perubahan organisasi tidak cukup dengan mengikuti fase-fase perubahan budaya perubahan organisasi, tetapi perlu juga difokuskan pada fase-fase perubahan yang terjadi di dalam setiap individu yang ada pada suatu organisasi. Model $A D K A R$ telah banyak digunakan untuk mengidentifikasi kesenjangan yang terjadi dalam proses perubahan dengan mendiagnosis resistensi karyawan untuk berubah, mendukung transisi karyawan dalam melalui proses perubahan, menetapkan rencana aksi dan prestasi, dan mengembangkan rencana manajemen perubahan bagi karyawan. Identifikasi terhadap faktor-faktor pembangun dan penghambat dalam $A D K A R$ merupakan langkah nyata dalam upaya mencapai keberhasilan perubahan. ${ }^{14}$

Tujuan Penelitian adalah melakukan analisis manajemen perubahan individu dalam revitalisasi Puskesmas di Kabupaten Sumedang.

\section{Metode}

Penelitian dilakukan pada Bulan Februari-Maret 2015 di Puskesmas Situ dan Puskesmas Paseh Kabupaten Sumedang. Subyek penelitian adalah tenaga Puskesmas dengan kriteria inklusi PNS dan memiliki masa kerja $>5$ tahun sedangkan kriteria eksklusi adalah tidak berada di tempat dan tidak bersedia. Paradigma penelitian adalah konstruktivisme sosial dengan desain penelitian deskriptif kualitatif dan strategi studi kasus

Pengumpulan data dilakukan dengan teknik wawancara mendalam terhadap 6 (enam) orang responden dan observasi terhadap situasi lokasi penelitian termasuk kegiatan lokakarya mini di Puskesmas. Selain itu dilakukan pengumpulkan dokumen, buku, dan laporan yang terkait. Selanjutnya dilakukan editing, reduksi, koding, kategorisasi, dan interpretasi data. Analisis dilakukan secara tematik menurut model manajemen perubahan ADKAR.

\begin{tabular}{|l|l|l|}
\hline$A$ & $\begin{array}{l}\text { Awareness : Kesadaran akan perlunya } \\
\text { perubahan }\end{array}$ \\
\hline$D$ & $\begin{array}{l}\text { Desire : Keinginan mendukung dan } \\
\text { berpartisipasi dalam perubahan }\end{array}$ \\
\hline$K$ & $\begin{array}{l}\text { Knowledge : Pengetahuan mengenai cara } \\
\text { melakukan perubahan }\end{array}$ \\
\hline$A$ & $\begin{array}{l}\text { Ability : Kemampuan untuk } \\
\text { mengimplementasikan perubahan }\end{array}$ \\
\hline$R$ & $\begin{array}{l}\text { Reinforcement : Penguatan untuk } \\
\text { mempertahankan perubahan }\end{array}$ \\
\hline
\end{tabular}

\section{Gambar 1 Model Manajemen Perubahan} ADKAR

\section{Hasil}

Hasil analisis data penelitian ini meliputi 35 halaman transkrip wawancara, 115 koding dan 19 sub kategori yang ditampilkan dalam 2 tema yaitu motivasi perubahan internal dan motivasi perubahan eksternal. Untuk menjamin trustworthiness penelitian ini maka dilakukan beberapa metode seperti yang disarankan oleh Guba. ${ }^{15}$ Sebelum dilaksanakan penelitian ini telah mendapatkan ethical clearance dari Komisi Etik. Bangunan perubahan individu pada revitalisasi Puskesmas menunjukkan bahwa urutan paling atas adalah blok reinforcement,yang merupakan tahap awal dalam membangun kesiapan individu untuk menghadapi perubahan dan kemudian melaksanakan tugas perubahan berikutnya. Inilah yang merupakan hasil dari perubahan individu sebagai fokus dari manajemen perubahan ADKAR. ${ }^{16}$

Knowledge, dan ability merupakan blok-blok yang melengkapi bangunan perubahan individu setelah awareness dan merupakan penopang bagi blok reinforcement. Pada tahap knowledge, individu tidak hanya menjadi tahu cara melakukan perubahan dan perilaku yang dibutuhkan untuk hal tersebut melainkan sesungguhnya mendapatkan fondasi bagi perubahan yang harus 
dilakukan. Membangun knowledge sesungguhnya juga membangun awareness. Ketika organisasi melakukan perubahan, sebenarnya sebagian besar individu tidak mempunyai pengetahuan dasar tentang alasan perubahan. ${ }^{12}$

"Kebetulan saya kuliah, dapat informasi yang lebih tentang apa sih sebenarnya, Puskesmas itu harus seperti apa." (Inf.05)

Ability individu dalam revitalisasi Puskesmas lebih banyak terbangun dengan adanya dukungan terutama yang berkaitan dengan mentoring. Individu dengan knowledge yang sebenarnya tidak memadai dapat cukup cakap melaksanakan perubahan setelah intens mendapatkan kontak dengan pihak penanggung jawab perubahan. Dalam hal ini pembinaan merupakan aplikasi dari keterampilan komunikasi pimpinan yang paling memengaruhi bagi ability individu. ${ }^{13}$ Fondasi bagi bangunan perubahan individu adalah blok awareness yang merupakan bentuk pemahaman setiap individu terhadap perubahan penyelenggaraan yang terjadi di puskesmas yang harus dilakukan. Pemahaman ini terbangun sebagai dampak adanya momen perubahan pembiayaan Puskesmas, pengamatan individu terhadap berbagai peningkatan yang dialami Puskesmas, dan komunikasi yang dilakukan individu tentang perubahan-perubahan yang terjadi di Puskesmas.

"Kalau eu ada perubahannya eu waktu Puskesmas ini ada eu bebas biaya. Jadi kelihatan gitu ada perubahannya. Itu otomatis juga kan yah enggak yang di pelayanan juga kan tapi semua program. Itu kan mungkin itu disambut juga oleh
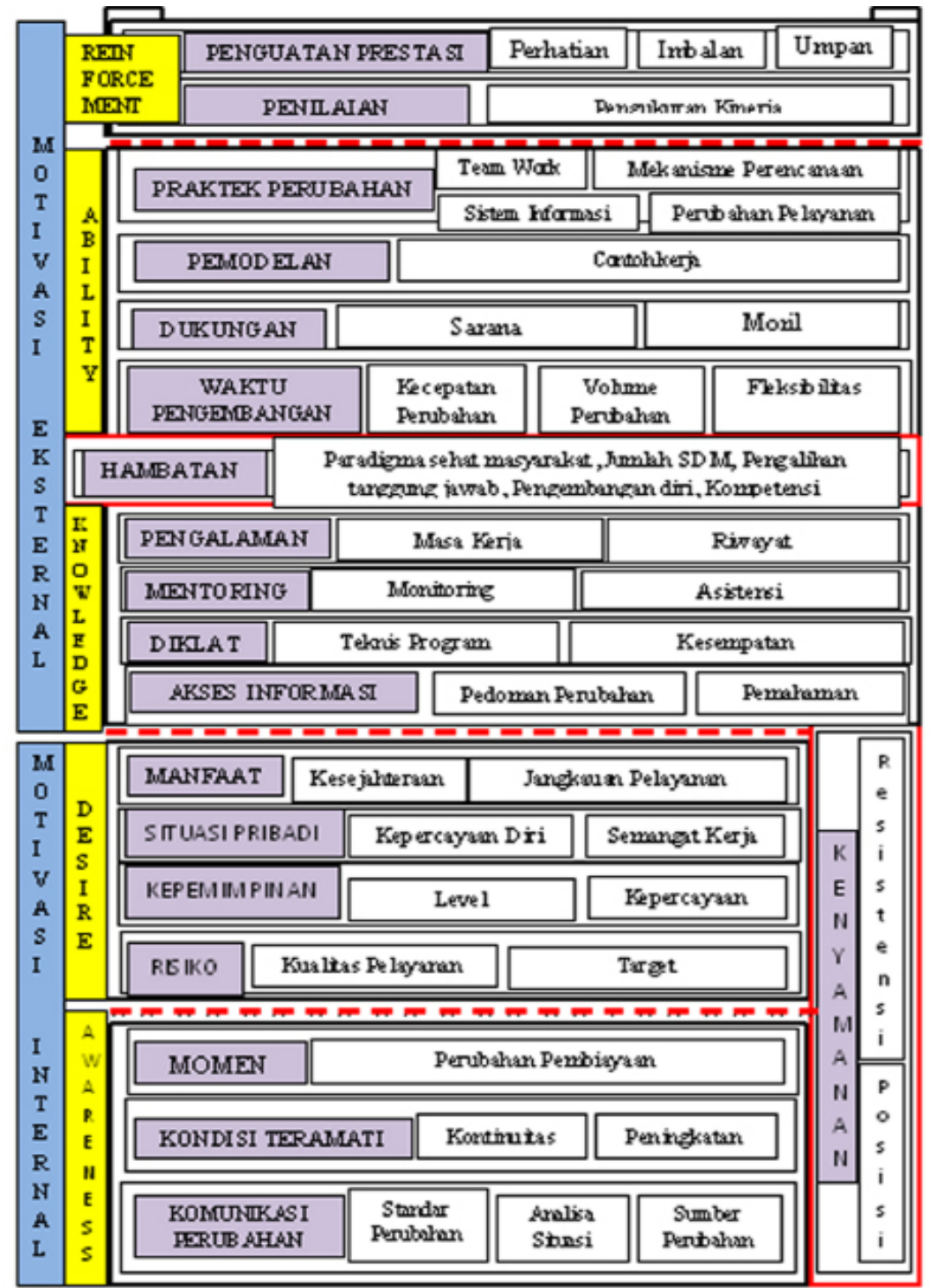

Gambar 2 Peta Konsep Bangunan Perubahan Individu dalam Revitalisasi Puskesmas di Kabupaten Sumedang 
masyarakat. Jadi kelihatan ya waktu itu karena pasiennya banyak ya waktu itu sampai sampai kita itu sampai jam berapa gitu yah kita melayani sampai penuh pokoknya."(Inf.06).

Kesediaan individu (desire) untuk turut berpartisipasi dalam suatu perubahan Puskesmas sangat tergantung pada kerja tim yang berlaku dalam berbagai perubahan yang harus dilakukan. Team work telah mendorong individu untuk mau ataupun tidak mau tetap melakukan tugas perubahan. Kerja sama dalam tim merupakan hal utama dalam menciptakan desire individu yang harus berubah. ${ }^{13}$

\section{Pembahasan}

Perubahan individu merupakan hasil dari manajemen perubahan organisasi yang akan menentukan keberhasilan perubahan organisasi, dengan tujuan terjadinya peningkatan kinerja organisasi. Sadar, mau, mencari tahu, mampu, dan siap dalam perubahan adalah keputusan individu yangmerupakanhasilketerampilanmenyelesaikan persaingan dorongan dalam dirinya. Berbagai keputusan tersebut merupakan motif individu untuk melakukan perilaku perubahan yang terhimpun dalam berbagai aktifitas perubahan untuk mendukung bentuk perubahan organisasi yang dilakukan. Terjadinya perbedaan aktifitas yang ditunjukkan oleh individu-individu di organisasi, saat melakukan perubahan disebabkan karena adanya perbedaan keterampilan individu dalam mengelola dorongan. Ketrampilan tersebut dipengaruhi oleh norma sosial, keberagaman nilai dan pengalaman yang dimiliki individu. ${ }^{17}$

Gaya perubahan kemudian menjadi hal yang menentukan keterampilan mengelola dorongan individu. Norma sosial yang mendorong setiap individu dalam melakukan aktifitas perubahan merupakan bentuk dari gaya perubahan yang dilakukan oleh pimpinan organisasi. Dengan gaya perubahan pula maka keberagaman nilai-nilai pribadi dan pengalaman individu dimunculkan untuk mengelola dorongan perubahan yang terjadi. Keberagaman merupakan salah satu tren perilaku organisasi yang tidak dapat dikesampingkan dalam mengelola akselerasi perubahan di tempat kerja. ${ }^{17}$

Perubahan individu sebagai suatu hasil pada akhirnya benar-benar terjadi pada periode perubahan. Fungsi implementasi pada manajemen perubahan organisasi sebagai bagian dari periode perubahan merupakan motivasi eksternal bagi knowledge dan ability individu untuk tahu dan berperilaku yang sesuai dalam menangani berbagai masalah dalam masa transisi perubahan. Kebijakan sumber daya manusia (SDM) dan kepemimpinan pada tahap implementasi dari fungsi manajemen merupakan peluang bagi terjadinyaproses pendidikan, pelatihandan praktek perubahan individu di Puskesmas. Pada akhirnya reinforcement bagi keberhasilan perubahan dan kesiapan individu menyongsong perubahan berikutnya dapat diperoleh dari fungsi evaluasi dan umpan balik oleh organisasi. Pengukuran kinerja yang jelas bagi setiap individu dengan menggunakan instrument penilaian pekerjaan oleh suatu organisasi merupakan salah bentuk penguatan keberhasilan perubahan yang terjadi.

Seluruh fungsi manajemen perubahan oleh organisasi akan membawa perubahan bagi setiap individu dalam suatu organisasi. Hal tersebut tergantung pada gaya perubahan yang dilakukan oleh pimpinan organisasi. Pola komunikasi yang terbuka dan gaya perubahan partisipatifcenderung akan menekan berbagai faktor penghambat dan sekaligus memperkuat faktor-faktor pembangun perubahan individu dalam revitalisasi Puskesmas.

Pada peta konsep manajemen perubahan individu, terlihat bahwa sikap permisif yang terjadi dalam organisasi dapat mengkonstruksi kenyamanan individu sehingga menghambat fondasi dan keputusan pribadi bagi perubahannya. Kondisi tersebut, ditambah dengan situasi SDM yang tidak sesuai akan menyebabkan seolah-olah organisasi mengizinkan individu untuk melakukan tugas hanya didalam lingkup kompetensinya atau bahkan diluar lingkup kompetensinya. Dalam perjalanan perubahan yang terjadi di Puskesmas, Dinas Kesehatan kabupaten selanjutnya menyerahkan perubahan tersebut kepada Kepala Puskesmas selaku bawahan. Pengetahuan tentang perubahan Puskesmas kemudian menjadi milik Kepala Puskesmas pun demikian halnya tugas membangun ability dan reinfoercement bagi individu Puskesmas.

Perubahan kepemimpinan Puskesmas yang terjadi di puskesmas pada akhirnya makan merupakan perubahan pada struktur pola komunikasi yang diterapkan di dalam organisasi Puskesmas. Bangunan perubahan yang terjadi pada individu dapat terbangun sejak dari fondasi dengan penerapan struktur pola komunikasi yang terbuka dan demokratis oleh kepala Puskesmas. Dengan struktur ini, semua anggota kelompok mendapat porsi komunikasi yang seimbang. ${ }^{18}$

Setiap individu yang bekerja di Puskesmas dengan pengalaman struktur pola komunikasi tersebut diatas, dapat membangun awareness, desire, knowledge dan ability serta mendapatkan reinforcement perubahan yang memadai. Mutasi kepemimpinan Puskesmas dapat menciptakan struktur pola komunikasi yang beragam bagi individu sehingga peningkatan kinerja individu tidak menjadi luaran perubahan Puskesmas.

Teori substantif yang dihasilkan melalui 
penelitian ini menunjukkan bahwa perubahan individu sebagai hasil dari manajemen perubahan mendahului perubahan organisasi. Perubahan organisasi membutuhkan perubahan manusia pengelolabaik dalam haljumlahmaupunkualitas. ${ }^{19}$

Penelitian dilakukan secara cross sectional sehingga hasil penelitian menunjukkan proses perubahan hanya terlihat pada saat penelitian berlangsung. Triangulasi terhadap sumber data hanya dilakukan dalam lingkup unit penelitian sehingga data manajemen perubahan organisasi tidak berasal langsung dari perencana reformasi sektor kesehatan yang berada di level pemerintah pusat. Peneliti tidak melakukan pendampingan perubahan dan penelitian ini bersifat restropektif sehingga hanya melihat proses perubahan yang sudah dilakukan. Konteks penelitian ini adalah penyelenggaraan revitalisasi Puskesmas sebelum terbitnya Permenkes No. 75 Tahun 2014 tentang Puskesmas.

Simpulan, Manajemen perubahan individu Puskesmas di Kabupaten Sumedang terbangun secara tidak utuh sehingga perubahan individu yang sudah terjadi menjadi rentan untuk menghadapi berbagai tugas perubahan berikutnya.

Perubahan perilaku organisasi Puskesmas lebih dahulu terjadi dibandingkan perubahan perilaku individu Puskesmas.Hasil penelitian menunjukkan bahwa, perubahan yang terjadi pada staf Puskesmas merupakan tanggung jawab penuh Kepala Puskesmas sebagai perpanjangan tangan dari Dinas Kesehatan Kabupaten. Indivdu dengan knowledge yang kurang memadai dapat cukup trampil untuk melakukan aktifitas perubahan dengan pendampingan dan penerapan teknik komunikasi yang tepat. Perubahan pada organisasi Puskesmas sangat ditentukan oleh fokus fungsi manajemen perubahan yang terjadi dan dilakukan oleh Dinas Kesehatan dalam periode pra perubahan yang juga merupakan titik kritis keberhasilan perubahan individu. Setiap individu di puskesmas perlu menyadari adanya suatu perubahan, untuk selanjutnya setiap individu di puskesmas membuat keputusan pribadi dan bersedia untuk ikut serta melakukan perubahan.

Saran, bagi sumber daya manusia di Puskesmas perlu aktif mencari informasi dan pengetahuan tentang berbagai hal baru yang harus dilakukan di Puskesmas serta berpartisipasi dalam proses perencanaan pembangunan kesehatan mulai dari tingkat desa, tingkat Kecamatan, dan dalam kegiatan perencanaan Puskesmas.

\section{Daftar Pustaka}

1. Departemen Kesehatan Republik Indonesia. Laporan akhir penelitian upaya revitalisasi pelayanan kesehatan Puskesmas dan jaringannya dalam rangka peningkatan kualitas pelayanan kesehatan. Surabaya: Departemen Kesehatan R.I;2006.

2. Sunjaya DK, Raksanagara AS, Setiawati EP, Pancari AD, editor. Seminar Nasional Reformasi Sektor Kesehatan Dalam Desentralisasi Di Indonesia: Tahun Kelima Pelaksanaan Kebijakan Desentralisasi Sektor Kesehatan Di Indonesia. Bandung: Program Studi Magister Ilmu Kesehatan Masyarakat Program Pascasarjana Universitas Padjadjaran; 2006.

3. Departemen Kesehatan Republik Indonesia. Laporan akhir puskesmas era desentralisasi dalam pengembangan sistem kesehatan kabupaten/kota (Tahap I : analisis situasi). Jakarta: Departemen Kesehatan RI; 2002.

4. Muninjaya AG. Konsep revitalisasi pelayanan kesehatan dasar. [diunduh 9 Oktober 2014]. Tersedia dari: muninjaya.com.

5. Keputusan Menteri Kesehatan Republik Indonesia tentang Kebijakan Dasar Puskesmas, 128, (2004).

6. Departemen Kesehatan Republik Indonesia. Membangun fondasi reformasi kesehatan: rekaman pembangunan kesehatan periode 1999-2004. Jakarta: Departemen Kesehatan RI; 2004.

7. Sopacua E, Handayani L. Potret pelaksanaan revitalisasi puskesmas. J Manajemen Pelayanan Kesehatan. 2008 [dunduh 10 Oktober 2014]; 11:27-31. Tersedia dari: http://jurnal.ugm.ac.id.

8. Clark H, Anderson AA. Theories of change and logic models: telling them apart; 2004 [diunduh 4 November 20142014]. Tersedia dari: http://www.theoryofchange.org.

9. Kasali R. Change. Jakarta: PT Gramedia Pustaka Utama; 2007.

10. Drummond-Hay R, Bamford D. A case study into planing and change management within the UK national health service. The International J of Public Sector Management. 2009 [diunduh 10 Oktober 2014]; 22(4):3243. Tersedia dari : http://www.emeraldinsight. com.

11. Setiawati EP. Nadeak W, Sendjaja TP, Djajasudarma F, Kurnani BA, Hariyadi D, Wahya, Sobarna C, Indira D, editor. Peranan sumber daya terhadap pencapaian kinerja program penanggulangan Tuberkulosis. Bandung: UNPAD Press; 2010.

12. Khatri P, Gulati K. Implanting Change in Organization Successfully. Asian J of Management Research. Review. 2010 [diunduh 10 Oktober 2014]; 1 NO 1:130-8. Tersedia dari : ipublishing.co.in. 
13. Kiani A, Shah H. An Application of ADKAR Change Model for the Change Management Competencies of School Heads in Pakistan. J of Managerial Sciences. 2014 [diunduh 10 Oktober 2014]; VIII No. 1:77-95. Tersedia dari : www.qurtuba.edu.pk.

14. Brand, CGM. Factors Influencing Change Management In A Selected Hospital In Saudi Arabia. [Tesis]. 2013 [diunduh 10 Oktober 2014]. Tersedia dari : scholar.sun.ac.za.

15. Shenton, AK. Strategies for ensuring trustworthiness in qualitative research projects. J Education For Information. 2004 [diunduh 20 Oktober 2014]; 22:63. Tersedia dari : http://www.crec.co.uk.

16. Prosci. Knowledge, ability, and reinforcement making the change; 2014 [diunduh 21 Oktober 2014]: Tersedia dari: http://www. change-management.com/tutorial-adkaroverview-mod3.htm.

17. McShane SL, Von Glinow, MA. Organizational Behavior. Edisi ke-4. New York: McGraw-Hill;2008.

18. Hersey P, Blanchard K. Manajemen perilaku organisasi : Pendayagunaan sumberdaya manusia. Jakarta; Erlangga; 1994.

19. Sunjaya DK. Perubahan organisasional dinas kesehatan, Studi kasus peningkatan fungsi regulasi Dinas Kesehatan Kota Bandung dan Kota Yogyakarta. Program Doktor Ilmu Kedokteran dan Kesehatan Fakultas kedokteran Universitas Gadjah Mada;2010. 